\title{
Chapter
}

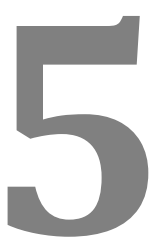

\section{ON-CHIP SAMPLE PREPARATIONS FOR POINT-OF-CARE CELLULAR ANALYSIS OF BLOOD}

Xichen Zhang, Leon W. M. M. Terstappen, and Markus Beck*

Medical Cell Biophysics, University of Twente, the Netherlands 


\section{Contents}

5.1. INTRODUCTION

5.2. REAGENT-FREE CELL SEPARATION BASED ON PHYSICAL CHARACTERISTICS........117

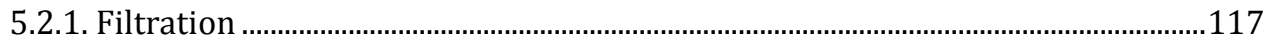

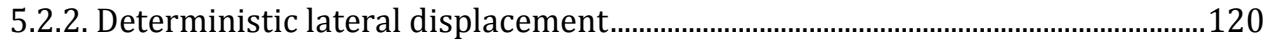

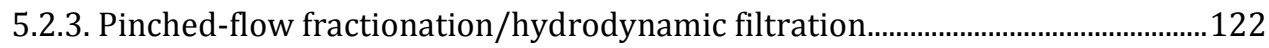

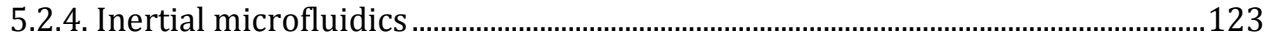

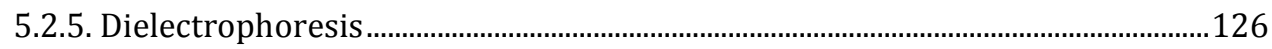

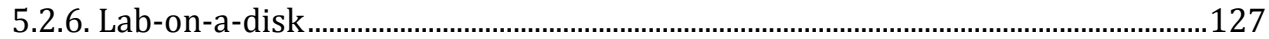

5.3. BIOMARKER-MEDIATED CELL IDENTIFICATION AND SORTING BASED ON

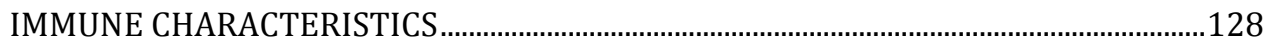

5.3.1. On-chip immunostaining and cell identification.....................................................128

5.3.2. On-chip immunomagnetic cell separation.............................................................131

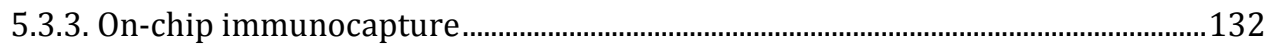

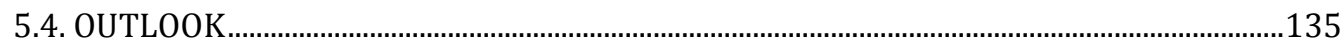

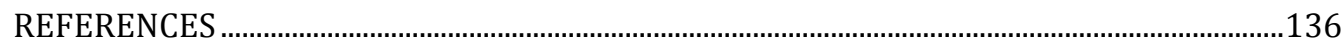




\subsection{INTRODUCTION}

Blood flows throughout the whole body in a vigorous manner as the entire blood volume is circulated every minute. It is physiologically important, as blood supports the homeostasis of the body by delivering oxygen and nutrients to every cell and transporting metabolic products between all types of tissues and organs. Additionally, the circulation allows cells of the immune system to travel to the desired site and perform immuno-surveillance in an efficient fashion. The clinical evaluation of the cellular composition of blood can provide important information on the body status, and abnormal test results implicate the presence of disease or organ malfunction. Therefore, blood contains a wealth of information that can provide an overview of the general health status of our bodies.

Cellular analysis of blood is widely used for medical diagnostics. A complete blood count (CBC) surveys the cellular constituents of whole blood with the quantification of each cell population (erythrocytes, leukocytes and platelets) and is routinely used to determine a person's health status. In a microliter of blood from a healthy donor, there are approximately 5 million erythrocytes (red blood cells [RBCs]), 150,000-450,000 platelets and 4000-11,000 leukocytes (white blood cells [WBCs]), which can be further classified into 5 subpopulations: monocytes, lymphocytes, neutrophils, basophils and eosinophils [1]. An abnormal CBC often indicates the presence of a medical condition or disease, such as infection, inflammation, anaemia or leukemia [2]. The CD4 count, measuring the number of CD4+ $\mathrm{T}$ lymphocytes, is widely used by medical professionals to monitor human immunodeficiency virus (HIV) progression [3]. With respect to malaria, the identification of parasites in RBCs and the quantification of parasitemia by examining blood smears is important to determine the patient's prognosis [4]. The presence of tumour cells in the blood (circulating tumor cells [CTCs]) is associated with poor prognosis, and their isolation and characterization can be used to guide therapy [5].

Sample preparation, including separation, isolation and exposure of cells to reagents, is crucial to cellular analysis. Depending on the diagnostic needs, target cells should be either fully isolated or exclusively distinguished prior to further characterization for improved specificity and sensitivity, because irrelevant cells in the blood might alter the condition of target cells or interfere with the analysis. The extreme heterogeneity in blood cell populations creates challenges in the sample preparation for cellular analysis of blood.

Most cellular analyses are performed in centralized laboratories, where sample preparation has to follow strict protocols with the aid of high-end external equipment. Accessibility of these tests at bedsides, in disaster areas and in low resource settings is challenging. 
To address these challenges, microfluidic-based lab-on-a-chip (LOC) technology proposes practical solutions. The innovative concept of miniaturizing conventional sample preparation into a microdevice is very attractive to perform cellular analysis of blood samples at point-of-care (POC). Compared with conventional off-chip sample preparation, the downscaled dimensions of microdevices allow for a reduced blood sample volume, which minimizes the discomfort and adverse effects of blood drawing, as well as reduced consumption of reagents, energy and time. In addition, the miniaturized size renders increased portability to enable sample preparation to be performed on site where it is needed. The integration of complex benchtop operations into a self-contained microdevice realizes a (semi-)automated processing step, greatly simplifying sample preparation and reducing manual errors for enhanced reproducibility.

This chapter summarizes the latest progress in LOC technology, with a focus on the development of sample preparation for the cellular analysis of blood samples. An overview of different approaches, which enable either partial or complete on-chip sample preparation, is presented. The approaches of on-chip cell separation and identification are grouped into two categories: a reagentfree strategy based on the diversity in physical signatures and a reagentbiomarker interaction strategy based on the difference in immunoaffinity. The principle of each approach and the details of specific microfluidic design are elaborated on, followed by a demonstration of diagnostic applications for relevant medical conditions. Then, the different approaches are assessed with respect to criteria such as simplicity, specificity and sensitivity. Finally, some recommendations on improving the current cell sampling techniques to achieve truly POC cellular analysis are proposed. 


\subsection{REAGENT-FREE CELL SEPARATION BASED ON PHYSICAL CHARACTERISTICS}

The heterogeneity of cells in blood is reflected in their diverse physical properties. In light of the physical variation among different cell populations, numerous separation principles have been developed and implemented in LOC systems. Cell size, shape, deformability, density and dielectric property are commonly used parameters to distinguish target cell populations. Physical separation based on these parameters neither consumes biochemical reagents for cell labeling nor for cell capture, as are so-called label-free approaches, thus achieving simple and reproducible on-chip sample preparation. In this section, recent progress in physical separation approaches is summarized.

\subsubsection{Filtration}

Cell size is the one of most noticeable properties when examining a blood smear with a microscope. Mechanical filtration is an effective approach for the separation of cells based on distinctive size. A well-established application is the separation of WBCs and RBCs in whole blood [6-9]. Bench-top filtration concepts using fibrous membranes (nitrocellulose [7], polycarbonate $[8,10]$, polyacrylamide [11]) can be simply down-scaled and implemented into microdevices. In such devices, whole blood flows perpendicularly to the membrane comprising a magnitude of pores of precisely controlled size, which allows the passage of cells smaller than a critical size and retains their larger counterparts. In addition to miniaturized membranes, obstacle microarrays can also enable an excellent sieving effect. A variety of array structures in terms of micropillars/microposts [12-14], microweirs [14] and microtraps [15] have been designed and fabricated. By tailoring the dimension and the geometry of obstacles as well as the spacing distances, the desired size cut-off can be achieved. Sample throughput can be enhanced by increasing the number of filtration units.

Although mechanical filtration is a very simple, versatile method that allows for high throughput, there are still two major challenges that have to be addressed. The first challenge is clogging, which is due to the dead-end filtration scheme (sample flows perpendicular to membranes or obstacle microarrays in a single channel, Figure 1i). Saturation of filtration units leads to decreased filtration efficiency and impractical regeneration of these units results in problems for continuous sample processing. The second challenge is regarding cell viability. Cells suffer from a risk of damage when moving under a high flow rate or squeezing through a filtration unit. Elevated shear stress and concentrated tensile stress compromise the viability of cells, reducing the potential for subsequent cell culture or molecular analysis.

Cross-flow filtration has been developed to overcome the clogging issue (Figure 1i). It consists of a main channel and one or more side channels, creating additional exits for sample fluid. After being introduced, sample fluid 
can be directed either into side channels through microfilters or remain within the main channel. Cells suspended in blood flow at a size-dependent tangential rate in the stream. Smaller cells are extracted into side channels through microfilters and travel to the corresponding outlets, while cells that are too large to pass through the microfilters are swept to the outlet of the main channel, without clogging the flow path [9]. Lee and co-workers developed a simple cross-flow filtration system with two inlet ports and two outlet ports. Buffer solution and blood sample were introduced into a channel and encountered an inclined silicon microfilter array where larger cells were diverted into a secondary channel and smaller cells travelled through the filters. With appropriate hydrodynamic pressure for both streams, the device can realize a $74 \%$ recovery of foetal nucleated RBCs and a $46 \%$ depletion of adult RBCs from mixed cell model [16] (Figure 1ii). In addition to the inclined orientation in the flow path, a microfilter array can also be arranged parallel to the flow path of the main channel. Chen et al. and Sethu et al. developed crossflow filtration systems with one main channel in the centre and two side channels in a parallel orientation. Micropillar [17] and microweir [18] arrays are located at the interfaces between the main and lateral channels, enabling cross flows. With the optimized flow dynamics, WBC-enriched and depleted blood fractions can be harvested from the outlets of main channel and lateral channels, respectively (Figure 1iii). In order to improve efficiency and purity in WBC enrichment, VanDelinder and co-workers developed a microdevice with a deep main channel for the passage of WBCs and an array of orthogonal, shallow side channels for the entrapment of RBCs [19] (Figure 1iv). As whole blood advances in the main channel, a perfusion flow through the side channels gradually washes away RBCs. This method achieved 4000-fold enrichment and $98 \%$ retention of WBCs from whole blood. Reverse-flow filtration provides another concept to prevent clogging and increase the life time of filtration units. McFaul and co-workers fabricated a microratchet array and employed an oscillatory flow to selectively regenerate the pores blocked by larger and less deformable cells [20] (Figure 1v).

To preserve cell viability, a 3D filtration system with 2 porous polydimethylsiloxane (PDMS) layers has been developed to provide a gentle capture to preserve cell integrity [21] (Figure 1vi). When cancer cells were trapped in the filtration units from the top layer, the bottom layer provided support in the opposite direction to compensate for tensile stress on the cells. More than $85 \%$ of the captured cancer cells remained intact. 
i) a)

b)

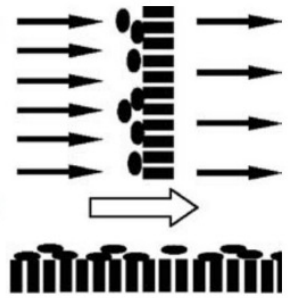

ii)
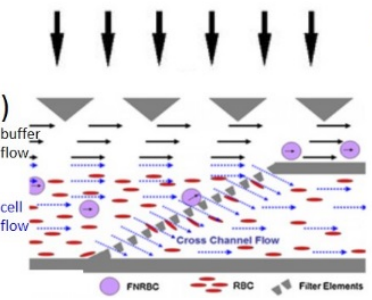

iii)

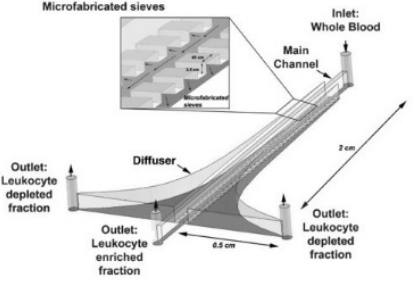

iv)

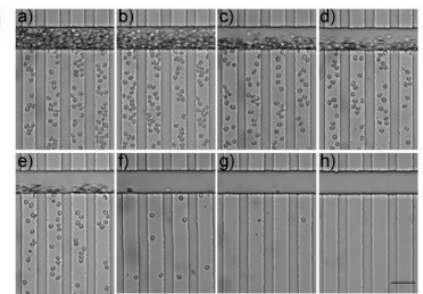

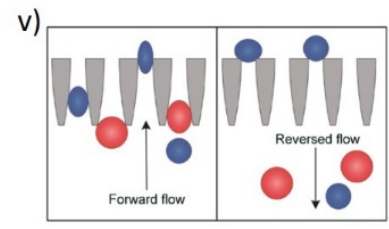

vi)

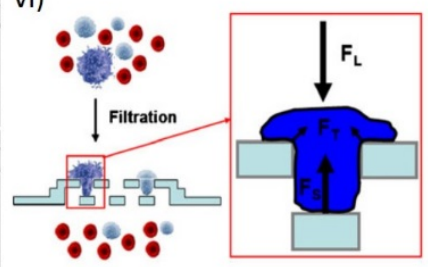

Figure 1. Schematic presentation of different filtration schemes and examples. i) Deadend and cross-flow filtration. ii) Separation of foetal nucleated RBCs (FNRBCs) and adult RBCs by a micropillar array inclined to flow direction. When the parallel flows of cell suspension (blue dash lines) and buffer (solid black lines) encounter the filter array, the smaller adult RBCs penetrate through the filters, whereas larger FNRBCs are diverted. iii) Separation of RBCs from whole blood by a microweir array parallel to the

flow direction. Insert shows the $40 \times 2.5 \mathrm{~mm}$ sieve structure and the arrangement connecting the main channel to the lateral channels. iv) Depletion of RBCs from whole blood by a microchannel array parallel to the flow direction. The horizontal main channel is $25 \mu \mathrm{m}$ deep for WBC enrichment, and the vertical channels are $3 \mu \mathrm{m}$ deep allowing the diverting of RBCs. Images a) to $h$ ) are the partial regions of the channel array at distances from $0-16.8 \mathrm{~mm}$ away from the beginning of the separation network with increments of $2.4 \mathrm{~mm}$. v) Ratchet cell-sorting. Smaller and more deformable cells can squeeze through the funnel constrictions during forward flow. However, they are unable to pass back through the funnels when the flow direction is reversed periodically to unclog the filter. vi) Filtration using a 3D microfilter device. Inset shows the applied forces on a trapped cell. $\mathrm{F}_{\mathrm{L}}$ : force caused by the fluidic flow pressure. $\mathrm{F}_{\mathrm{S}}$ : supporting force from the bottom. $\mathrm{F}_{\mathrm{T}}$ : tensile stress force on the plasma membrane. i) copyright 2007 Springer [9]; ii) copyright 2010 Elsevier [16]; iii) copyright 2006 Royal

Society of Chemistry [18]; iv) copyright 2007 American Chemistry Society [19]; v) copyright 2012 Royal Society of Chemistry [20]; vi) copyright Springer [21]. 


\subsubsection{Deterministic lateral displacement}

Deterministic lateral displacement (DLD) is another well-established cell separation approach based on size under continuous flow conditions. This approach was first developed by Huang and co-workers, who applied this technology to sort particles of different sizes [22]. A recent review provides indepth understanding of the mechanism underlying this size-based particle separation [23]. As illustrated in Figure 2i [24], a microfluidic channel hosts a specific arrangement of microposts, which splits the sample flow into different streamlines and determines the trajectory of accommodating cells. Cells suspended in the fluid are distributed in different streamlines. When a cell is smaller than a critical diameter and the centre falls within the width of the first streamline, a drag force will be dominant to keep the cell unperturbed to follow a zigzag route in the first streamline. Meanwhile, a larger cell will fall into an outward streamline, which deflects from the first one, thus becoming displaced from the smaller counterpart. By shifting each succeeding post row laterally at a predefined distance from its predecessor, periodical deflection of the cell path will be created, leading to an amplified displacement of cell trajectory and achieving cell separation. In the review, McGrath and coworkers have proposed a toolbox in which the influence of micropost array (size, shape, orientation and spacing) on the critical size for cell displacement and the consideration of microfluidic phenomena (profile of laminar flow, diffusion and fluidic resistance) on the performance of DLD are summarized in detail. This toolbox is very beneficial as a design aid to develop a tailored microdevice to separate cells of specific sizes. Cancer cells spiked into whole blood have been recovered from the mixture with more than $85 \%$ efficiency using DLD [25]. Advanced DLD designs are capable of separating whole blood into multiple fractions [24], for instance, the fractionation of platelets with different sizes by employing a series of different micropost arrays [26] (Figure 2ii-iii). Each array has a slightly different critical diameter. Using this method, size-discriminating resolution was enhanced step by step and a successful separation between WBCs, RBCs and platelets was achieved.

The concentration of cells in the sample fluid determines the efficiency of cell separation. In whole blood samples, the dense concentration of RBCs will increase the likelihood of RBC contamination in outward streamlines due to the overcrowded RBC population in the first streamline. Moreover, nonspecific interactions between microposts and suspended cells will increase flow resistance and finally lead to clogging, especially for blood samples with a dense cell concentration. Therefore, blood samples with a high cell concentration need to be diluted prior to processing. Because DLD is designed for separating rigid and spherical particles, another challenge of efficient blood cell separation lies in the non-spherical shape and deformability of RBCs [27]. Although improved efficiency has been demonstrated, the greatly increased complexity in microarray fabrication and largely reduced throughput outweigh the benefit $[28,29]$. 

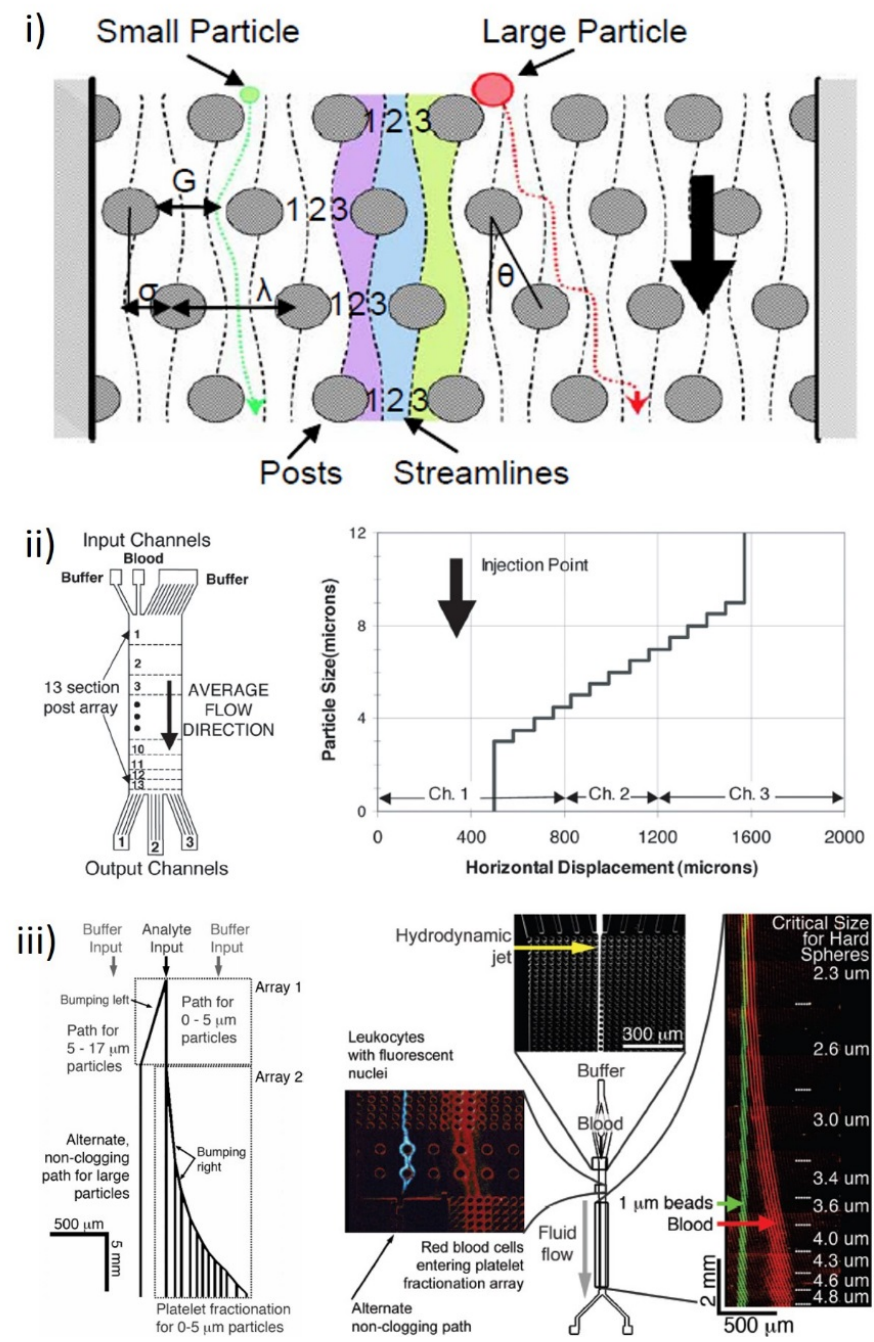

Figure 2. i) Schematic presentation of the DLD principle. The orientation of streamlines induced as a consequence of lateral micropost shifting and the distinctive trajectory of particles falling into different streamlines. ii) Left: A DLD device designed to separate WBCs from RBCs and platelets. A cascade of 13-section post arrays with different critical diameters and spacings were employed to separate cells with a range of diameters. Right: The predicted size-dependent displacement of cells travelling through the post arrays. The lateral position of the blood injection point at the top of the device is shown. Three exit channels at the bottom of the device are used to collect

the fractionated blood. iii) Left: Diagram of ideal particle paths in the platelet fractionation device. WBCs are moved to the left by Array 1 into a channel that runs parallel to but is not in connection with the platelet fractionation array, Array 2. It is composed of a series of 11 post arrays, each with increasing critical particle size for increasing lateral displacement. Right: Micrographs of various cells in the device at three locations: whole blood injection at inlet (upper), WBCs separation at Array 1 (left) and platelet fractionation at Array 2 (right). i) and ii) copyright 2006 National Academy of Sciences, U.S.A [24]; iii) copyright 2008 Royal Society of Chemistry [26]. 


\subsubsection{Pinched-flow fractionation/hydrodynamic filtration}

Pinched-flow fractionation and hydrodynamic filtration have shown potential in size-dependent cell separation. Their operation principles are similar. When a sample fluid with a low Reynolds number is traveling in a microchannel, the trajectories of suspended cells are determined by the paths of streamlines into which they are falling [30]. The distribution of cells in streamlines is closely related to cell size and flow profile. Therefore, tuning the flow profile via the optimization of flow rate, variation in the geometric design of microchannels and arrangement of the inlet and outlet can achieve size-dependent cell sorting.

Pinched flow fractionation was first proposed by Yamada and co-workers for precise particle separation [31]. During the operation, two laminar streams were pumped through a pinched segment before entering a broadened channel. One stream was diluted blood and the other was buffer solution, which flowed at a higher rate to push blood cells against the sidewall in the pinched segment, resulting in an alignment of the cell mixture. Smaller cells were distributed in the streamline closer to the sidewall than their larger counterparts. At the boundary between the pinched segment and the broadened channel, a transition in flow profile occurred. Dramatically spread steamlines amplified the position difference between smaller and larger cells in the pinched segment and led to a cell dispersion perpendicular to the flow direction according to their sizes in the broadened channel. The broadened channel was then branched into multiple outlets in an optimized arrangement. Enriched RBCs have been reported to be harvested from a predetermined outlet of a pinched microchannel [32] (Figure 3i).

Hydrodynamic filtration has been demonstrated by Yamada and Seki using devices that consist of a straight main channel with a single inlet and a number of perpendicular branched channels [33]. By pumping the sample fluid along the main channel and withdrawing it from branched channels, cells are aligned along the sidewall of the main channel. Smaller cells distribute adjacent to the sidewall, suffer less flow resistance and enter branched channels upstream. Larger cells are still far away from the sidewall, thus being forced to flow straight. Every time the fluid is drawn into the branched channel, larger cells were brought closer to the sidewall and eventually flew into the branch channels. This channel network enables displaced cell alignment against the sidewall of the main channel based on its size, therefore offering a promising solution of WBC enrichment from whole blood (Figure 3ii).

The desired flow rate is crucial to manipulating the trajectory of cells in the channel. This demand for an external pumping system increases the complexity of the applications. A decrease in cell sorting efficiency due to a high cell concentration necessitates a dilution step prior to sorting. 

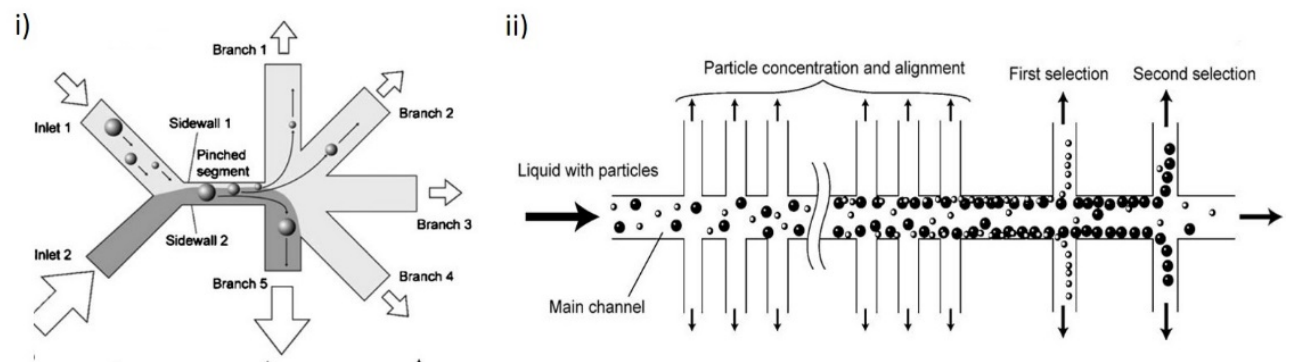

Figure 3. i) Schematic presentation of particle concentration and classification in a microchannel having multiple branch points and side channels. ii) Schematic presentation of pinched flow fractionation. i) copyright 2005 Royal Society of Chemistry [32] ii) copyright 2005 Royal Society of Chemistry [33].

\subsubsection{Inertial microfluidics}

The contribution of inertia in microfluidics phenomena has not received significant attention in the last decade. Recent discoveries overturn the traditional understanding that microfluidics is associated with negligible inertia. Instead, inertia becomes apparent in a fluid with a high Reynolds number and contributes significantly to microfluidic phenomena [34,35]. Di Carlo explicitly elaborated on a dominant effect, inertial migration of particles, which is widely exploited for cell separation [36]. Such migration is induced by inertial lift forces intrinsic to cell motion in confined channel flows. In Poiseuille flow, two opposing lift forces act perpendicular to the flow direction on a moving cell. The wall-induced lift drives the cell away from the channel wall with a force decreasing with the distance from the channel wall. In contrast, the shear gradient induced lift pushes the cell towards regions of higher shear gradient, which means towards the channel wall in the parabolic velocity profile of Poisseuille flow. Interaction of the two forces on a given type of cells results in an equilibrium at a focused streamline, which defines a characteristic trajectory for effective cell separation [36] (Figure 4i). Key parameters to control inertial lift equilibrium and cell focusing are channel geometry, flow rate, cell size and deformability. After reviewing these parameters for tunable cell separation, Amini and co-workers proposed tips to design appropriate microfluidics to sort cells with different properties (shape, size and deformability) based on the latest development of inertial microfluidics [37]. With respect to microfluidic design, a multitude of geometries - straight [35,38,39], curved [40], spiral [41], pinched [34] and alternative expansion and contraction edges [42] - have been developed for cell sorting (Figure 4ii-vi). Several cell sorting applications based on these principles have been demonstrated, for example, the isolation of CTCs from the other cell populations in whole blood [42]. The deformation of cells, in particular CTCs under high shear stress, was reported to have an impact on cell 
focusing in the channel, while the influence on separation efficiency was still inconclusive $[34,41]$. To pursue efficient separation of cells that are prone to deformation, the difference in deformability was also exploited in inertial microfluidics to enrich CTCs from diluted blood samples [39]. With the aid of size and deformability as dual distinctive features, the fractionation of diluted blood into RBCs, platelets, peripheral blood mononucleated cells and granulocytes was achieved by real-time deformability cytometry [38]. For further increased efficiency and purity, the size- and deformability-based separation was cascaded in series to achieve a 100 -fold enrichment of platelets from diluted blood [40]. Under high-flow-rate conditions, sensitive cells subject to strong inertial interaction are seriously stressed. The risk of cell damage questions the validity of subsequent cellular analysis after separation. To address this issue, a soft inertial microfluidic system developed by $\mathrm{Wu}$ and co-workers employed a sheath flow to reduce shear stress and protect fragile cells during separation [35]. Escherichia coli (E. coli) was successfully isolated from diluted blood and the viability of $E$. coli was verified by comparing the protein content of cells before and after separation.

Similar to hydrodynamic filtration, the performance of an inertial microfluidic system is highly dependent on precise flow control. This strict requirement of an external pumping system may narrow down the scope of applications, in particular, for adverse operation conditions and low-resource settings. Moreover, sample concentration is another limitation. Whole blood with a high cell concentration must be diluted in a pre-treatment step to maintain separation efficiency, thus reducing the value in the simplicity of this approach. 
i)

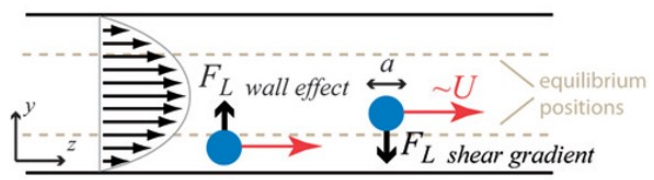

ii)
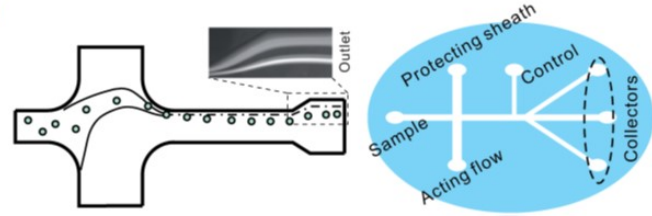

iii)
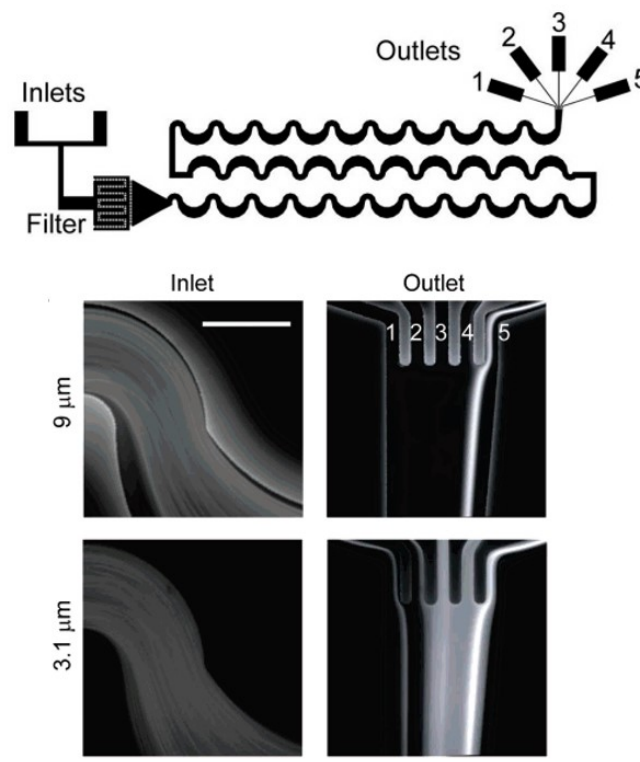

iv)

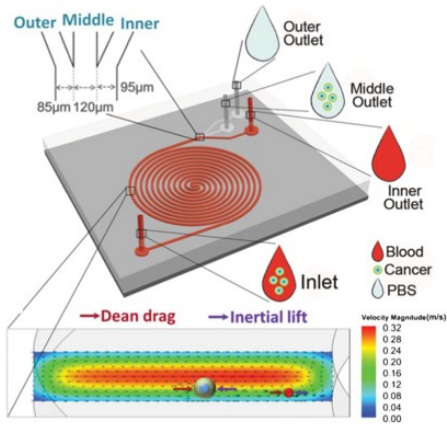

v)
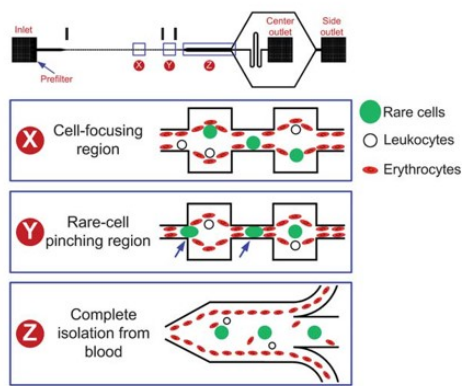

vi)

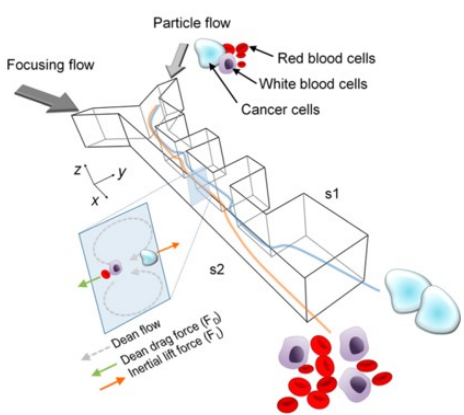

Figure 4. Principle of particle separation by inertial microfluidics (i) and layout of inertial microfluidics with straight (ii), curved (iii), spiral (iv) and pinched channels (v) and a channel with alternate side edges (vi). i) copyright 2009 Royal Society of Chemistry [36]; ii) copyright 2009 Royal Society of Chemistry [35]; iii) copyright 2008 American Society of Chemistry [40]; iv) copyright 2012 Royal Society of Chemistry [41] v) copyright 2011 Royal Society of Chemistry [34]; vi) copyright 2013 American Chemistry Society [42]. 


\subsubsection{Dielectrophoresis}

Cells in the blood stream are a heterogeneous population of biological particles. Each subpopulation possesses intrinsic dielectric properties, which are closely related to membrane capacitance and cytoplasm resistance $[43,44]$. Dielectrophoresis (DEP) will occur when blood is exposed to a non-uniform electric field. Depending on the frequency of the field, polarized cells can either exhibit positive DEP (attraction to high electric field) in low conductive fluid or negative DEP (repulsion from high electric field) $[45,46]$ in physiological media with high conductivity. This selective cell response makes dielectrophoresis a powerful tool to manipulate the dynamic behaviour of cells in blood for the purpose of separation and sorting.

Incorporating DEP into microdevices can be easily achieved. Well-developed micro electro mechanical systems (MEMS) technology enables a straightforward implementation of electrode and exquisite control of electric field in microdevices. DEP can be implemented in a very efficient way in microfluidics, as the small dimensions in microfluidic devices allow for the generation of intense electric field gradients using rather low voltages.

Microfluidic DEP technology for cell sorting can be grouped into field-flow fractionation, i.e. the deflection of cells from their streamlines and the capture of cells by the dielectrophoretic force. DEP field-flow fractionation technology with continuous flow has a striking advantage for high throughput sample preparation. The working principle is well elaborated by Lee et al. [47]. and Yang et al. [48]. When cells flow through a straight microchannel subject to an electric field, they experience three acting forces: DEP force, hydrodynamic force and gravity. By tuning the electric field (voltage and frequency) in a custom manner, the desired equilibrium of DEP force and gravity will levitate cells with varying dielectric properties and densities to distinct streamlines. The parabolic profile-induced velocity variance will allow cells to be eluted from the microchannel at different times. In addition, split microchannels downstream will harvest cells spatially separated in the main stream. One of the pioneering works achieved an elegant WBC 3-part differentiation by this technique [48]. Recently, the separation of CTCs (Figure 5i) [49-51], platelets $[52,53]$ and pathogens (bacterial cells [54,55], yeast cells [56]) from whole blood were also demonstrated with a recovery rate greater than $90 \%$.

DEP-assisted cell trapping is another strategy to achieve cell separation in a still fluid. In this concept, electrode microarrays function as steric traps to attract cells with a positive DEP response. Different patterns of microarrays linear post [57], interdigitated [58,59] and spiral - were developed. (Figure 5iiiv) This approach is suitable for submicron organism separation in blood samples. Plasmodium falciparum-infected RBCs [44] and E. coli [58] were demonstrated to be captured from blood and released upon electric field turnoff. 
As this approach requires exquisite electric control and flow control, it appears impractical for low-resource settings.

(i)

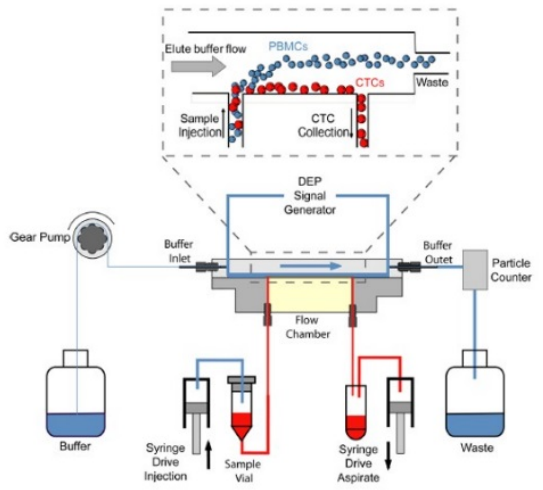

(iii)

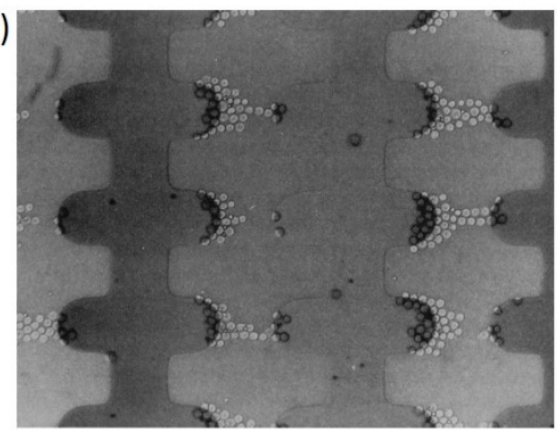

(ii)

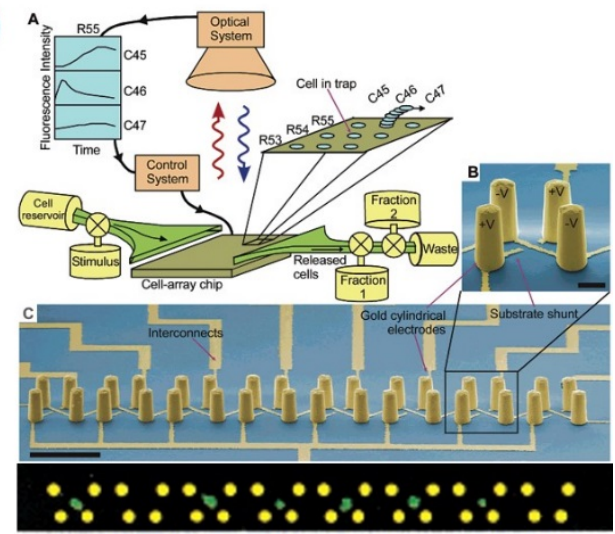

(iv)

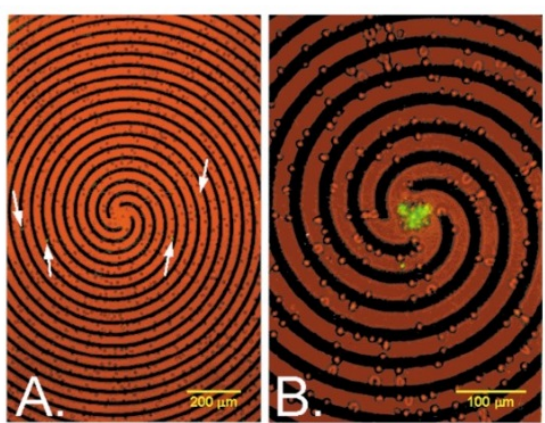

Figure 5. Microfluidics DEP devices. (i) DEP field-flow fractionation cell sorter for CTC isolation. (ii) Top, linear electrode array illustration; bottom, image of single cell capture. (iii) Interdigitated electrode array with cancer cells trapped at tips after blood removal. (iv) Distinct distribution of normal erythrocytes (edge of electrode) and $P$. falciparum-infected erythrocytes (centre of the spiral). i) copyright 2012 American Institute of Physics [49]; ii) copyright 2002 American Society of Chemistry [57]; iii) Copyright 1995 National Academy of Sciences, U.S.A. [59]; iv) copyright 2002 Royal Society of Chemistry [44].

\subsubsection{Lab-on-a-disk}

Cell density is another common physical property use to separate different cell populations in blood. Centrifugal approaches are particularly applicable in the extraction of blood constituents (erythrocytes and buffy coat) from different sediment layers. The lab-on-a-disk technology successfully miniaturizes the bench-top centrifugation protocol into an on-chip sampling step. Compared with the aforementioned LOC systems, the centrifugal lab-on-a-disk platform offers striking advantages in flow control. Instead of pressure-driven flow, sample handling in the lab-on-a-disk platform is simply driven by a 
conventional spindle motor, thus eliminating the need for an external pumping system. Centrifugal actuation independent of fluid properties, such as $\mathrm{pH}$ or conductivity, renders robustness in handling heterogeneous blood samples. The recent advances in the lab-on-a-disk platform for cell analysis were well summarized by Burger et al. [60]. Separation of the entire cellular constituent in whole blood can be readily achieved by plasma sedimentation in the lab-ona-disk platform employing straight [61], curved [62], azimuthally inclined [63] and spiral channels [64]. Recently, more and more attention has been drawn to selective separation of target cell populations from whole blood. A density gradient has been employed to separate WBCs from RBCs [65] or to enrich basophils [66] from peripheral human blood.

Although the lab-on-a-disk platform exhibits broader compatibility with different sample fluids and fewer constraints on external equipment, it still has its own limitations in terms of unidirectional flow and difficulty in extracting a very small cell population.

\subsection{BIOMARKER-MEDIATED CELL IDENTIFICATION AND SORTING BASED ON IMMUNE CHARACTERISTICS}

Compared with physical properties, cellular immunoaffinity is more potent to improve specificity in cell separation and achieve explicit cell identification. Biomarkers on cell membranes, e.g. surface antigens, are the immunological fingerprint of a cell population. The exclusive key-lock interaction between biomarkers and relevant biomolecules can be employed to identify and sort different cell populations in blood.

\subsubsection{On-chip immunostaining and cell identification}

The current gold standard for cell identification is flow cytometry. In this technology, cells pre-stained with fluorophore-labelled antibody are identified by passing through excitation laser beams and optical detectors in a serial manner. The test requires the operation of bulky instruments and bench-top sample preparation performed by skilled personnel in a well-equipped research environment.

Recent developments in microfluidics make promising progress in enabling cytometry technology for POC blood diagnostics. One pioneering concept uses microfluidic cell counting chambers with integrated reagents for on-chip immunostaining and a portable fluorescence imaging instrument for the detection of stained cells [67]. Unlysed whole blood flows into the chambers driven by capillary forces, and antibodies are released into the sample after the inflow has stopped. Fluorescence imaging after $30 \mathrm{~min}$ incubation yields sufficient contrast between cells and background without the need for a washing step. The prerequisite of on-chip staining under such conditions is 
homogenous mixing of blood and integrated reagents. To achieve even distribution of the reagent in blood, a polymer matrix is incorporated in a microdevice to release embedded reagents in a controlled manner upon contact with blood. This is the major research area of interest in our group. Beck and co-workers developed a self-contained chip with on-chip sample preparation for CD4 counting [67]. One side of the chip was covered with a manually deposited dry gelatine layer, which contained antibodies against CD3 $(\alpha \mathrm{CD} 3)$ and antibodies against CD4 ( $\alpha \mathrm{CD} 4)$. The chip was simply filled with whole blood through capillary action. The well-defined height of the chamber and image area of the fluorescence imager were used to meter the blood volume. The principle of on-chip sample preparation lies in a passive release scheme. Diffusion-controlled antibody release only starts when a certain degree of gelatine swelling is reached after blood inflow. This release delay is beneficial to prevent antibody wash-off in the chip (Figure 6i). By tuning the preparation of gelatine layers (thickness and degree of physical crosslinking), optimal release delay was achieved to maintain homogeneous antibody distribution in the chip, meanwhile ensuring more than $80 \%$ antibody fractional release within $10 \mathrm{~min}$ for rapid and sufficient immunostaining of target cells [68] (Figure 6ii). The stained cells were imaged by a fluorescence analyser and the analysis of the obtained image yielded the cell count. Thermally activated release in the same chip format was employed to demonstrate temperature-switched immunostaining [69]. In this work, gelatine/antibody layers were produced by inkjet printing, which turns the labour-intensive preparation to a semi-automatic process and improves layer reproducibility. The layers were subject to an appropriate maturation process to increase the degree of physical crosslinking in gelatine, resulting in a dense matrix network to retain antibody during blood inflow. On-demand antibody release after inflow can be triggered by heating the layer over the sol-gel transition temperature of gelatine. Elevated temperature led to gelatine dissolution to release embedded antibody in a rapid manner (Figure 6iii). Such concept of initially preventing release (during inflow), followed by a triggered instantaneous and complete release on demand successfully achieved uniform and complete on-chip immunostaining. Compared with the passive release scheme, this active release scheme offers better temporal control for the onchip sample preparation and can be beneficial for other biological assays, which requires a series of mixing steps. A similar concept was reported by Jin and co-workers [70], who achieved on-chip antibody release via the dissolution of poly(vinylpyrrolidone) (PVP) nanofibers for $E$. coli identification. Another approach to trigger the release of reagents for on-chip sample preparation is $\mathrm{pH}$-responsive release. Mortato and co-workers immobilized poly(methacrylic acid) microgels with embedded fluorophore-labelled antibody in a microfluidic channel [71]. The filling of whole blood at physiological $\mathrm{pH}$ induces maximum swelling of the microgel, thus enabling the release of reagent to stain $\mathrm{T}$ lymphocytes and $\mathrm{B}$ lymphocytes on chip but without the possibility of influencing the timing of the release externally. 
On-chip sample preparation enabled by controlled reagent release greatly simplifies the conventional staining protocol, including metering, pipetting, vortexing and rinsing. Despite that, it also faces unique challenges. Because all concepts in this approach aim for POC applications, in particular for lowresource settings, the functionality and integrity of both polymer matrix and embedded reagents must be verified in a less controlled environment with a broad span of temperature and humidity, which mimics the conditions in rural areas.

i)

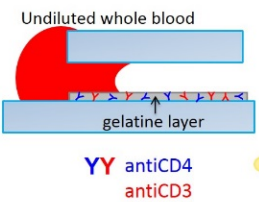

ii)

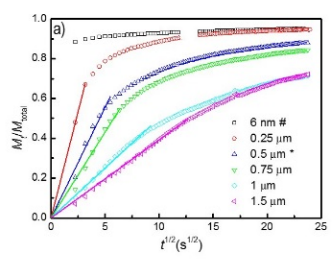

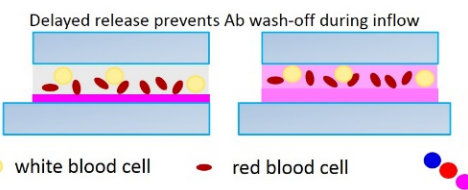
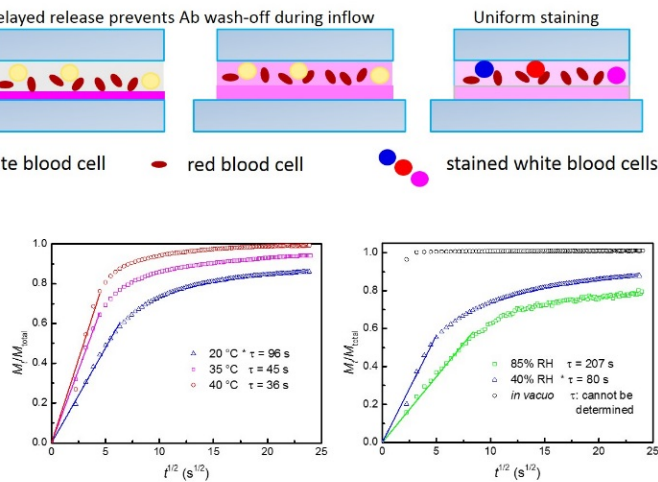

iii)
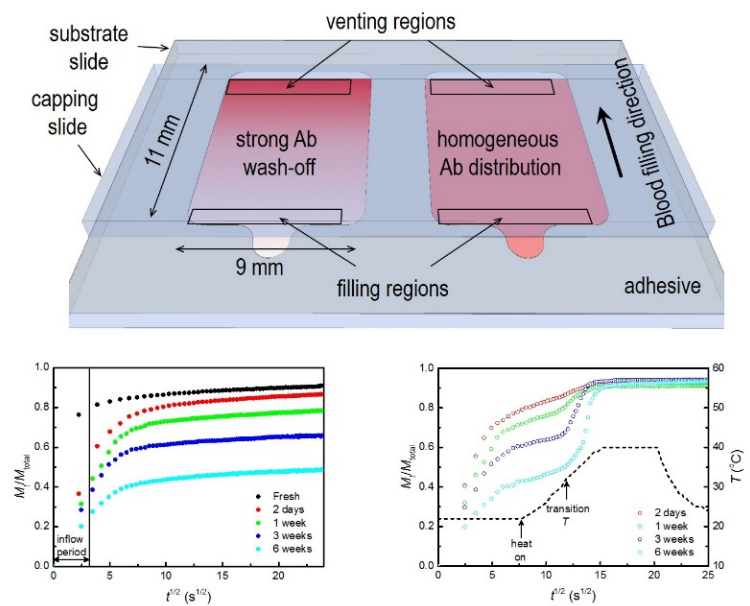

Figure 6. i) Schematic presentation of on-chip sample preparation for CD4 count. ii) Tuning antibody release kinetics by different layer preparation. iii) The influence of delayed release on the homogeneity of antibody distribution (upper). Layer maturation-induced delayed release and temperature-triggered release (lower). i) copyright 2012 Royal Society of Chemistry [67]; ii) copyright 2016 Royal Society of Chemistry [68]; iii) [69]. 


\subsubsection{On-chip immunomagnetic cell separation}

In addition to fluorophores, magnetic particles are also widely used to label antibodies that can recognize specific surface antigens. The coupling of antibody-coated magnetic particles against target cells has been reported to achieve highly selective immunomagnetic separation from bulky cell mixtures [72]. Implementing this separation scheme into microdevices can further enhance the separation purity and efficiency due to increased magnetic field gradients.

A one-step immunomagnetic separation of $\mathrm{T}$ lymphocytes from whole blood was realized on a simple microchannel [73]. Anti-CD3-coated magnetic beads were first introduced into the channel and accumulated at a precise location where permanent magnets were placed. This formed bead beds that served as a regional binding site to capture $\mathrm{T}$ lymphocytes in the subsequent blood flow (Figure 7i). In a similar concept, CTC-spiked whole blood was pre-stained with anti-epithelial cell adhesion molecule (anti-EpCAM) functionalized magnetic particles and flowed through a microchannel, which was closely above a magnetic array. By tuning the flow rate, the CTCs were separated from blood and deposited at the bottom of the channel with an $85 \%-90 \%$ capture rate [74]. In a more complex format, a planar array of magnetic stripes in a microchannel was designed [75] (Figure 7ii). Whole blood was injected into the microchannel and flowed over the magnetic array. WBCs coupled with anti-CD45 functionalized magnetic particles were clearly shown to deviate from the flow direction and proceed along the orientation of the magnetic strip. However, the track of RBCs was not deflected. This distinct flow pattern allows for excellent WBC separation. Saliba and co-workers developed a hexagonal array of magnetic ink patterned at the bottom of a microchannel. After the filling of antibody-coated magnetic beads into the channel, an external vertical magnetic field was applied to align free-moving beads into columns, which were anchored on top of the ink dots [76] (Figure 7iii). The self-assembled 3D magnetic trap array was successfully demonstrated to capture leukemia cells [76] and CTCs [77] from whole blood.

A minor concern of this approach lies in the interference from RBCs. In deoxygenated blood, the reduced form of iron-bearing haemoglobin may render RBCs with a paramagnetic property [78]. Despite the intrinsic magnetapheresis of RBCs being much weaker than that of target cells coupled to antibody-mediated magnetic particles, the purity of target cells isolated from whole blood must be further verified. 
(i)

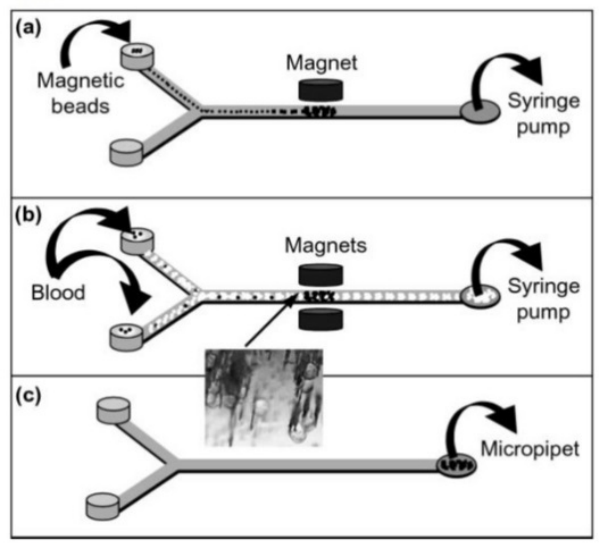

(ii)

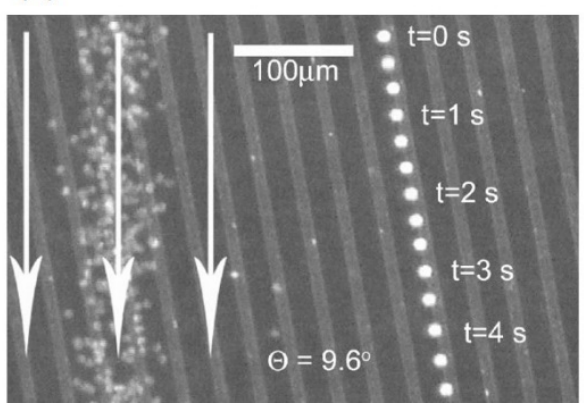

(iii)
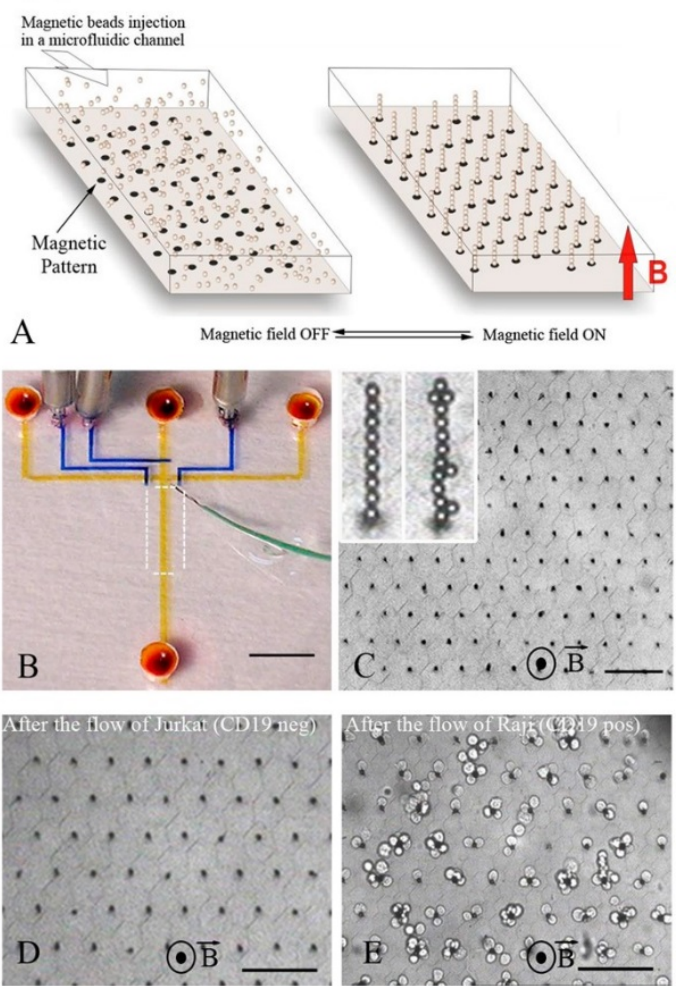

Figure 7. Magnetic-activated cell capture. (i) Immunomagnetic separation of $\mathrm{T}$ lymphocytes using a Y-intersection device. (ii) A single magnetically (and fluorescently) labelled leukocyte follows the magnetic stripes (right), while unlabeled erythrocytes follow the fluid direction (left). White arrow, fluid direction. (iii) The alignment and anchorage of antibody- coated magnetic beads for leukemia cell capture. i) copyright 2004 Royal Society of Chemistry [73]; ii) copyright 2004 American Institute of Physics [75]; iii) [76].

\subsubsection{On-chip immunocapture}

Specific adhesion of cells on a surface immobilized with a given ligand provides another strategy to address poor selectivity and low efficiency in physicalbased cell separation. Adhesion-based microdevices for cell separation have gained increasing attention due to their specificity and reliability as well as their label-free operation. The outcome of cell capture in microdevices is influenced by the employment of a ligand molecule, the device design and the applied flow rate. The affinity between the ligand molecule and the cell determines the adherence force between the cell and the surface. The shear stress induced by the geometry of the microchannel and flow rate diminishes 
cell adhesion [79]. Therefore, a successful application demands a thorough optimization of all three factors.

Antibodies are the most common ligand molecules due to the well-exploited antigen-antibody interaction for cell capture. Epithelial cell adhesion molecule (EpCAM) is a diagnostic marker for a variety of cancers. Nagrath and coworkers constructed a microchannel hosting an anti-EpCAM immobilized micropost array to capture CTCs from whole blood [80]. A $99 \%$ detection rate and greater than $50 \%$ capture purity were reported. In addition to relying on a single type of antibody for cell capture, a panel of antibodies was immobilized on the bottom surface of a microchannel to maximally match the phenotype of circulating endothelial progenitor cells for higher capture efficiency in blood [81]. In CD4 count application, diverse concepts were developed on the basis of the capture of CD4+ $\mathrm{T}$ lymphocytes [82-85]. Wang and co-workers captured all $\mathrm{CD} 4{ }^{+}$cells in a microtrap array and labelled captured cells with $\alpha \mathrm{CD} 3$-enzyme conjugates in a sandwich manner for chemiluminescence detection [82]. Cheng and co-workers excluded the influence of monocytes in CD4 count by a serial capture of monocytes and CD4+ $\mathrm{T}$ lymphocytes on a planar surface [84]. By using the same $\alpha \mathrm{CD} 4$ for immobilization, micropost arrays were found to be more efficient than a planar surface in the same microchannel in capturing $\mathrm{CD}^{+} \mathrm{T}$ lymphocytes due to increased surface areas [85]. Apart from microarray and channel surfaces, peptide-functionalized alginate hydrogel was also employed to capture cells in a microdevice [86]. A striking advantage is that the reversibly crosslinked alginate can be dissolved to release captured cells for further analysis. Microbeads are another carrier for antibody immobilization: a group of densely packed micobeads in a microchannel was able to capture $E$. coli with excellent efficiency from 91-95 \% [87]. 
(i)

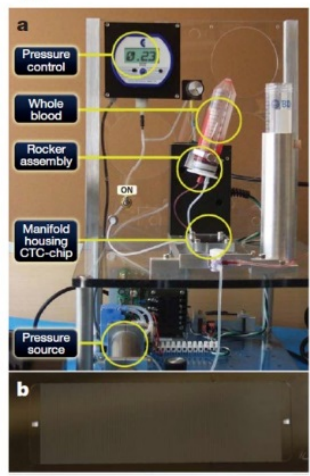

(ii)

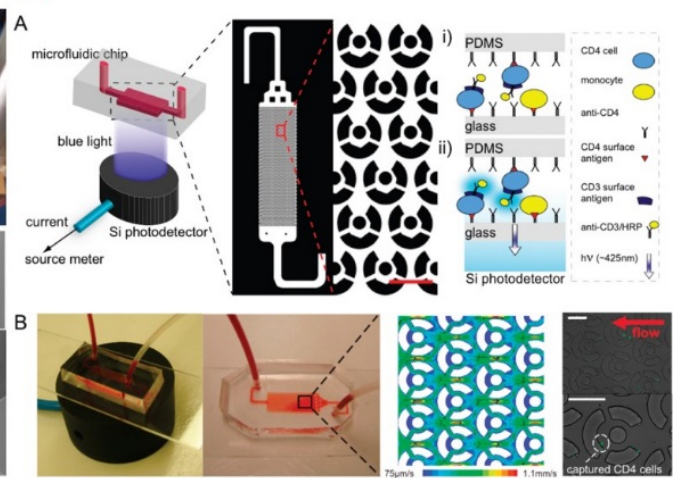

(iii)

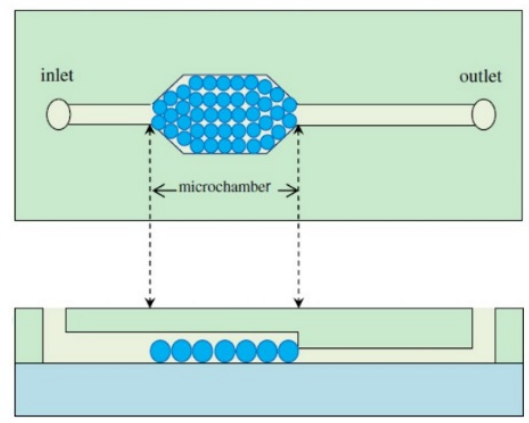

Figure 8. Adhesion-based cell capture. (i) Overall and detailed picture of CTC isolation system. a, workstation; d, lung cancer cell captured by antibody coated micropost array (ii) Schematic diagrams and pictures of a microdevice hosting an antibodycoated microtrap array for capturing $\mathrm{CD} 4^{+} \mathrm{T}$ lymphocytes using chemiluminescencebased detection. (iii) Schematic of the microchannel packed with antibody coated glass beads for $E$. coli capture. The thickness step of the channel ensures monolayer formation and prevents washing away of beads. i) copyright 2007 Nature publishing [80]; ii) copyright 2010 American Chemistry Society [82]; iii) copyright 2010 Springer [87].

Aptamers, short-chain oligonucleotides, recently receive growing attention as they show great potential to selectively target desired cell types [88]. The immobilization of aptamer onto the surface of the microchannel is accomplished via the biotin-avidin interaction. An interesting microdevice with an aptamer-functionalized microwell array was tested to capture cancer cells from whole blood [89]. By optimizing the size of the microwells, single-cell occupancy was obtained as high as $88 \%$. Three different aptamers: sgc8, TD05 and Sgd5 immobilized onto the planar surface of microchannels were employed to target CCL-119 T-cells, Ramos cells and Toledo cells, respectively in whole blood. A 135-fold enrichment was obtained with greater than $96 \%$ purity, suggesting profound specificity and selectivity in cell separation $[90,91]$. Thanks to this high yield of cell enrichment, aptamer-based 
microdevices were capable of detecting the chemiluminescence produced by leukemia cells down to 10 cells $\mathrm{ll}^{-1}$ in the blood sample [92].

External pumping-enabled Precise flow enabled by external pumping to achieve the efficient capture. Therefore, the availability of immuno-capturebased cellular analysis is limited only to well-equipped research environments.

\subsection{OUTLOOK}

Over the last decade, fast-paced advancement in LOC technology has driven the development of a diversity of on-chip sample preparation concepts for cellular analysis of blood samples. Few successful concepts are applied into practice for routine POC blood tests. The underlying reason is that the potential of POC testing is not fully reached by the current concepts. An ideal LOC device for POC blood tests should be able to take an input of whole blood and output a result. In addition, the entire process is completely automated and accessory free. There are two issues holding back the application of current concepts. First, the required accessories for fluid actuation and (electric and magnetic) field implementation prevent the use of on-chip cell separation and sorting at the POC. Second, current LOC devices for cellular analysis do not meet the need for comprehensive blood tests, in particular, the genetic analysis of small subpopulations of cells, such as for the analysis of CTCs and foreign pathogens in blood samples. To overcome this limitation, the following issues need to be addressed. From the operational point of view, a microdevice should enable self-regulated fluid delivery (i.e. capillary driven) and on-chip sample-reagent mixing (i.e. diffusion-driven, possibly in combination with controlled reagent release) to secure (semi)-automatic sample preparation. From a functional point of view, successive preparation and analysis steps may require segmented compartments (e.g. for cell identification and capture, cell lysis, biomolecular sensing), which should be implemented into microdevices to fulfil the requirement of multi-step sample preparation for blood tests. In other words, the simplicity of existing POC solutions such as lateral flow assays must be combined with the performance of advanced LOC technology. 


\section{REFERENCES}

1. K.E. Barett, S. Boitano, S.M. Barman, H.L. Brooks, Ganong's Review of Medical Physiology, McGraw-Hill Medical, New York, USA, 2010, p.p. 523.

2. $\quad$ B.J. Bain. N. Engl. J. Med. 353 (2005) 498-507.

3. $\quad$ D.S. Stein, J.A. Korvick, S.H. Vermund. J. Infect. Dis. 165 (1992) 352-363.

4. $\quad$ N.J. White. N. Engl. J. Med. 335 (1996) 800-806.

5. W.J. Allard, L.W.M.M. Terstappen. Clin. Cancer Res. 21 (2015) 2883-2885.

6. A. Bruil, W.G. van Aken, T. Beugeling, J. Feijen, I. Steneker, J.G. Huisman, H.K. Prins. J. Biomed. Mater. Res. 25 (1991) 1459-1480.

7. X. Yang, O. Forouzan, T.P. Brown, S.S. Shevkoplyas. Lab. Chip 12 (2012) 274-280.

8. W.R. Rodriguez, N. Christodoulides, P.N. Floriano, S. Graham, S. Mohanty, M. Dixon, M. Hsiang, T. Peter, S. Zavahir, I. Thior, D. Romanovicz, B. Bernard, A.P. Goodey, B.D. Walker, J.T. McDevitt. PLoS Med. 2 (2005) e182.

9. H.M. Ji, V. Samper, Y. Chen, C.K. Heng, T.M. Lim, L. Yobas. Biomed. Microdevices 10 (2008) 251-257.

10. U. Dharmasiri, M.A. Witek, A.A. Adams, J.K. Osiri, M.L. Hupert, T.S. Bianchi, D.L. Roelke, S.A. Soper. Anal. Chem. 82 (2010) 2844-2849.

11. D.S. Reichmuth, S.K. Wang, L.M. Barrett, D.J. Throckmorton, W. Einfeld, A.K. Singh. Lab. Chip 8 (2008) 1319-1324.

12. P. Wilding, L.J. Kricka, J. Cheng, G. Hvichia, M.A. Shoffner, P. Fortina. Anal. Biochem. 257 (1998) 95-100.

13. R. Carlson, C.V. Gabel, S.S. Chan, R.H. Austin, J.P. Brody, J. Winkleman. Mol. Biol. Cell 8 (1997) 2407-2407.

14. H. Mohamed, L.D. McCurdy, D.H. Szarowski, S. Duva, J.N. Turner, M. Caggana. IEEE Transactions on Nanobioscience 3 (2004) 251-256.

15. S.J. Tan, L. Yobas, G.Y. Lee, C.N. Ong, C.T. Lim. Biomed. Microdevices 11 (2009) 883-892.

16. D. Lee, P. Sukumar, A. Mahyuddin, M. Choolani, G. Xu. J. Chromatogr. A 1217 (2010) 1862-1866.

17. X. Chen, D. Cui, C. Liu, H. Li, J. Chen. Anal. Chim. Acta 584 (2007) 237-243.

18. P. Sethu, A. Sin, M. Toner. Lab. Chip 6 (2006) 83-89.

19. V. VanDelinder, A. Groisman. Anal. Chem. 79 (2007) 2023-2030.

20. S.M. McFaul, B.K. Lin, H. Ma. Lab. Chip 12 (2012) 2369-2376.

21. S. Zheng, H.K. Lin, B. Lu, A. Williams, R. Datar, R.J. Cote, Y.C. Tai. Biomed. Microdevices 13 (2011) 203-213.

22. L.R. Huang, E.C. Cox, R.H. Austin, J.C. Sturm. Science 304 (2004) 987-990.

23. J. McGrath, M. Jimenez, H. Bridle. Lab. Chip 14 (2014) 4139-4158.

24. J.A. Davis, D.W. Inglis, K.J. Morton, D.A. Lawrence, L.R. Huang, S.Y. Chou, J.C. Sturm, R.H. Austin. Proc. Natl. Acad. Sci. U. S. A. 103 (2006) 14779-14784.

25. K. Loutherback, J. D'Silva, L.Y. Liu, A. Wu, R.H. Austin, J.C. Sturm. Aip. Advances 2 (2012) 042107.

26. D.W. Inglis, K.J. Morton, J.A. Davis, T.J. Zieziulewicz, D.A. Lawrence, R.H. Austin, J.C. Sturm. Lab. Chip 8 (2008) 925-931.

27. K.K. Zeming, T. Salafi, C.H. Chen, Y. Zhang. Sci. Rep. 6 (2016) 22934.

28. K. Loutherback, K.S. Chou, J. Newman, J. Puchalla, R.H. Austin, J.C. Sturm. Microfluid Nanofluidics 9 (2010) 1143-1149. 
29. M. Al-Fandi, M. Al-Rousan, M.A.K. Jaradat, L. Al-Ebbini. Robot Comput. Integr. Manuf. 27 (2011) 237-244.

30. D.R. Gossett, W.M. Weaver, A.J. Mach, S.C. Hur, H.T.K. Tse, W. Lee, H. Amini, D. Di Carlo. Anal. Bioanal. Chem. 397 (2010) 3249-3267.

31. M. Yamada, M. Nakashima, M. Seki. Anal. Chem. 76 (2004) 5465-5471.

32. J. Takagi, M. Yamada, M. Yasuda, M. Seki. Lab. Chip 5 (2005) 778-784.

33. M. Yamada, M. Seki. Lab. Chip 5 (2005) 1233-1239.

34. A.A.S. Bhagat, H.W. Hou, L.D. Li, C.T. Lim, J.Y. Han, Lab Chip 11 (2011) 1870-1878.

35. Z.G. Wu, B. Willing, J. Bjerketorp, J.K. Jansson, K. Hjort. Lab. Chip 9 (2009) 1193-1199.

36. D. Di Carlo. Lab. Chip 9 (2009) 3038-3046.

37. H. Amini, W. Lee, D. Di Carlo. Lab. Chip 14 (2014) 2739-2761.

38. O. Otto, P. Rosendahl, A. Mietke, S. Golfier, C. Herold, D. Klaue, S. Girardo, S. Pagliara, A. Ekpenyong, A. Jacobi, M. Wobus, N. Topfner, U.F. Keyser, J. Mansfeld, E. Fischer-Friedrich, J. Guck. Nat. Methods 12 (2015) 199-202.

39. S.C. Hur, N.K. Henderson-MacLennan, E.R. McCabe, D. Di Carlo. Lab. Chip 11 (2011) 912-920.

40. D. Di Carlo, J.F. Edd, D. Irimia, R.G. Tompkins, M. Toner. Anal. Chem. 80 (2008) 2204-2211.

41. J. Sun, M. Li, C. Liu, Y. Zhang, D. Liu, W. Liu, G. Hu, X. Jiang. Lab. Chip 12 (2012) 3952-3960.

42. M.G. Lee, J.H. Shin, C.Y. Bae, S.Y. Choi, J.K. Park. Anal. Chem. 85 (2013) 6213-6218.

43. P.R. Gascoyne, J.V. Vykoukal. Proc. IEEE Inst. Electr. Electron. Eng. 92 (2004) 22-42.

44. P. Gascoyne, C. Mahidol, M. Ruchirawat, J. Satayavivad, P. Watcharasit, F. Becker. Lab. Chip 2 (2002) 70-75.

45. R.S. Thomas, H. Morgan, N.G. Green. Lab. Chip 9 (2009) 1534-1540.

46. S. Park, M. Koklu, A. Beskok. Anal. Chem. 81 (2009) 2303-2310.

47. D. Lee, B. Hwang, B. Kim. Micro and Nano Systems Letters 4 (2016) 2-11.

48. J. Yang, Y. Huang, X.B. Wang, F.F. Becker, P.R. Gascoyne. Biophys. J. 78 (2000) 2680-2689.

49. V. Gupta, I. Jafferji, M. Garza, V.O. Melnikova, D.K. Hasegawa, R. Pethig, D.W. Davis. Biomicrofluidics 6 (2012) 24133.

50. J. Yang, Y. Huang, X.B. Wang, F.F. Becker, P.R. Gascoyne. Anal. Chem. 71 (1999) 911-918.

51. D.J. O'Shannessy, D.W. Davis, K. Anderes, E.B. Somers. Biomark Insights 11 (2016) 7-18.

52. N. Piacentini, G. Mernier, R. Tornay, P. Renaud. Biomicrofluidics 5 (2011) 34122-341228.

53. M. Yamashita, S. Miyata, S. Takeuchi, H. Inoue. Conf. Proc. IEEE Eng. Med. Biol. Soc. 2013 (2013) 4462-4465.

54. $\quad$ S. Park, Y. Zhang, T.H. Wang, S. Yang. Lab. Chip 11 (2011) 2893-2900.

55. I.F. Cheng, C.C. Lin, D.Y. Lin, H.C. Chang. Biomicrofluidics 4 (2010) 034104.

56. A. Valero, T. Braschler, N. Demierre, P. Renaud. Biomicrofluidics 4 (2010) 022807.

57. J. Voldman, M.L. Gray, M. Toner, M.A. Schmidt. Anal. Chem. 74 (2002) 3984-3990. 
58. J. Suehiro, D. Noutomi, M. Shutou, M. Hara. J. Electrostat. 58 (2003) 229-246.

59. F.F. Becker, X.B. Wang, Y. Huang, R. Pethig, J. Vykoukal, P.R. Gascoyne. Proc. Natl. Acad. Sci. U. S. A. 92 (1995) 860-864.

60. R. Burger, D. Kirby, M. Glynn, C. Nwankire, M. O'Sullivan, J. Siegrist, D. Kinahan, G. Aguirre, G. Kijanka, R.A. Gorkin, 3 ${ }^{\text {rd }}$, J. Ducree. Curr. Opin. Chem. Biol. 16 (2012) 409-414.

61. L. Riegger, M. Grumann, J. Steigert, S. Lutz, C. P. Steinert, C. Mueller, J. Viertel, 0. Prucker, J. Ruhe, R. Zengerle, J. Ducree. Biomed. Microdevices 9 (2007) 795-799.

62. J. Zhang, Q. Guo, M. Liu, J. Yang. J. Micromech. Microeng. 18 (2008) 125025-125030.

63. S. Haeberle, T. Brenner, R. Zengerle, J. Ducree. Lab. Chip 6 (2006) 776-781.

64. D.J. Kinahan, S.M. Kearney, M.T. Glynn, J. Ducree. Sens Actuators, A 215 (2014) 71-76.

65. S.T. Moen, C.L. Hatcher, A.K. Singh. PLoS One 11 (2016) e0153137.

66. H. Shiono, S. Ogawa, T. Matsui, S. Niwata, T. Okada, Y. Ito. J. Physiol. Sci. 60 (2010) S173.

67. M. Beck, S. Brockhuis, N. van der Velde, C. Breukers, J. Greve, L.W.M.M. Terstappen. Lab. Chip 12 (2012) 167-173.

68. X. Zhang, D. Wasserberg, C. Breukers, L.W.M.M. Terstappen, M. Beck. Analyst 141 (2016) 3068-3076.

69. X. Zhang, D. Wasserberg, C. Breukers, L.W.M.M. Terstappen, M. Beck. ACS Appl. Mater. Interfaces (2016) resubmitted after revision.

70. S. Jin, M. Dai, B. Ye, S.R. Nugen. Microsyst. Technol. 19 (2013) 2011-2015.

71. M. Mortato, L. Blasi, G. Barbarella, S. Argentiere, G. Gigli. Biomicrofluidics 6 (2012) 44107.

72. I. Safarik, M. Safarikova. J. Chromatogr. B 722 (1999) 33-53.

73. V.I. Furdui, D.J. Harrison. Lab. Chip 4 (2004) 614-618.

74. K. Hoshino, Y.Y. Huang, N. Lane, M. Huebschman, J.W. Uhr, E.P. Frenkel, X. Zhang. Lab. Chip 11 (2011) 3449-3457.

75. D.W. Inglis, R. Riehn, P. Austin. Appl. Phys. Lett. 85 (2004) 5093-5095.

76. A.E. Saliba, L. Saias, E. Psychari, N. Minc, D. Simon, F. C. Bidard, C. Mathiot, J.Y. Pierga, V. Fraisier, J. Salamero, V. Saada, F. Farace, P. Vielh, L. Malaquin, J.L. Viovy. Proc. Natl. Acad. Sci. U. S. A. 107 (2010) 14524-14529.

77. D. Horak, Z. Svobodova, J. Autebert, B. Coudert, Z. Plichta, K. Kralovec, Z. Bilkova, J.L. Viovy, J Biomed Mater Res A 101 (2013) 23-32.

78. F. Paul, S. Roath, D. Melville, D.C. Warhurst, J.O. Osisanya. Lancet 2 (1981) 70-71.

79. T.F. Didar, M. Tabrizian. Lab. Chip 10 (2010) 3043-3053.

80. S. Nagrath, L.V. Sequist, S. Maheswaran, D.W. Bell, D. Irimia, L. Ulkus, M.R. Smith, E.L. Kwak, S. Digumarthy, A. Muzikansky, P. Ryan, U.J. Balis, R.G. Tompkins, D.A. Haber, M. Toner. Nature 450 (2007) 1235-1239.

81. B.D. Plouffe, T. Kniazeva, J.E. Mayer, S.K. Murthy, V.L. Sales. The FASEB Journal 23 (2009) 3309-3314.

82. Z. Wang, S.Y. Chin, C.D. Chin, J. Sarik, M. Harper, J. Justman, S.K. Sia. Anal. Chem. 82 (2010) 36-40.

83. X. Cheng, D. Irimia, M. Dixon, K. Sekine, U. Demirci, L. Zamir, R.G. Tompkins, W. Rodriguez, M. Toner. Lab. Chip 7 (2007) 170-178. 
84. X. Cheng, A. Gupta, C. Chen, R.G. Tompkins, W. Rodriguez, M. Toner. Lab. Chip 9 (2009) 1357-1364.

85. N.N. Watkins, U. Hassan, G. Damhorst, H. Ni, A. Vaid, W. Rodriguez, R. Bashir. Sci. Transl. Med. 5 (2013) 214-224.

86. B.D. Plouffe, M.A. Brown, R.K. Iyer, M. Radisic, S.K. Murthy. Lab. Chip 9 (2009) 1507-1510.

87. X. Guan, H.J. Zhang, Y.N. Bi, L. Zhang, D.L. Hao. Biomed. Microdevices 12 (2010) 683-691.

88. H. Ulrich, J.E. Ippolito, O.R. Pagan, V.A. Eterovic, R.M. Hann, H. Shi, J.T. Lis, M.E. Eldefrawi, G.P. Hess. Proc. Natl. Acad. Sci. U. S. A. 95 (1998) 14051-14056.

89. Q. Chen, J. Wu, Y. Zhang, Z. Lin, J.M. Lin. Lab. Chip 12 (2012) 5180-5185.

90. J.A. Phillips, Y. Xu, Z. Xia, Z.H. Fan, W. Tan. Anal. Chem. 81 (2009) 1033-1039.

91. Y. Xu, J.A. Phillips, J. Yan, Q. Li, Z.H. Fan, W. Tan. Anal. Chem. 81 (2009) 7436-7442.

92. W. Liu, H. Wei, Z. Lin, S. Mao, J.M. Lin. Biosens. Bioelectron 28 (2011) 438-442. 
Chapter 5 